\title{
MIDAS
}

Museus e estudos interdisciplinares

$3 \mid 2014$

Varia e dossier temático: "Museos y participación biográfica"

\section{Maria Vlachou - Musing on Culture: Management, Communications and Our Relationship with People}

\section{Dália Paulo}

\section{OpenEdition}

\section{Journals}

Edição electrónica

URL: http://journals.openedition.org/midas/438

DOI: $10.4000 /$ midas. 438

ISSN: 2182-9543

\section{Editora:}

Alice Semedo, Paulo Simões Rodrigues, Pedro Casaleiro, Raquel Henriques da Silva, Ana Carvalho

\section{Refêrencia eletrónica}

Dália Paulo, « Maria Vlachou - Musing on Culture: Management, Communications and Our Relationship with People », MIDAS [Online], 3 | 2014, posto online no dia 16 maio 2014, consultado no dia 22 setembro 2020. URL : http://journals.openedition.org/midas/438 ; DOI : https://doi.org/10.4000/ midas. 438

Este documento foi criado de forma automática no dia 22 setembro 2020.

\section{(i) (ㅇ)

Midas is licensed under a Creative Commons Attribution-NonCommercial-ShareAlike 3.0 International License 


\title{
Maria Vlachou - Musing on Culture: Management, Communications and Our Relationship with People
}

\author{
Dália Paulo
}

\section{REFERÊNCIA}

Vlachou, Maria. 2013. Musing on Culture: Management, Communications and Our Relationship with People. Lisboa: Bypass Editions. 157 páginas, ISBN 978-989-97189-3-7.

1 Musing on Culture: Management, Communications and Our Relationship with People é o resultado do olhar atento, do pensamento crítico e da reflexão séria, persistente e continuada que Maria Vlachou ${ }^{1}$, especialista em gestão e comunicação cultural, dedicou à cultura através do seu blogue Musing on Culture (http://musingonculturept.blogspot.pt). De 2010 a 2012 publicou mais de 121 artigos; tendo destes, selecionado 32 textos para o livro, remetendo, no final de cada um, para outros textos do blogue relacionados com o tema.

2 A edição organiza-se por cinco áreas temáticas: o lugar da cultura; a gestão cultural; as pessoas e a comunicação; o marketing e museus; e conta com o prefácio de Jorge Silva Melo, encenador e diretor artístico dos Artistas Unidos, que sintetiza desta forma a ação reflexiva da autora: «Maria - thinking, annotating - does not wish to "stay where we are"» (p. 8) e de Michael Kaiser, presidente do Kennedy Center for the Performing Arts (Washington, D.C.), que enfatiza: «this volume raises issues and begins conversations that must continue for years, perhaps for decades» (p. 9). É um desinquietar e um sentimento de se estar perante um desafio, que, acima de tudo, coloca como foco do nosso pensamento (cultural workers) os Outros. Trata-se de um livro-vanguarda, quer pelas referências (nacionais e internacionais) que utiliza, quer pela pertinência dos temas abordados, que nascem de um olhar aturado e, 
simultaneamente, fascinado pela vida e pelos desafios que se colocam (diariamente) a quem trabalha na área cultural.

Biodiversidade (com a sua definição) é a palavra escolhida por Maria Vlachou para começar o blogue e o livro. Esta opção revela o pensamento plural da autora e a sua inquietação sobre a necessidade de refletir sobre as políticas e práticas culturais e o seu impacto na vida das pessoas, na transformação do seu quotidiano e pensamento, atuando como um lugar de (des)encontros.

o livro Musing on Culture apresenta-se num formato (quase) de livro de bolso, com uma opção gráfica muito apelativa e que nos agarra de imediato pela contemporaneidade e pela leitura acessível. A edição, ao contrário do blogue, em português e inglês, é exclusivamente em língua inglesa, uma escolha que permite atingir outros leitores, diminuir custos de impressão e que, simultaneamente, se escuda na versão portuguesa online.

5 Pode colocar-se a questão da pertinência desta edição, uma vez que os artigos estão disponíveis na internet; em nosso entender é fundamental a reunião em livro do pensamento crítico e atento da autora, quer pela quase ausência no cenário editorial português de ensaios sobre as questões culturais (com algumas exceções de autores como António Pinto Ribeiro, Guilherme de Oliveira Martins ou Manuel Maria Carrilho) quer por uma questão mais simbólica, como seja a de materializar o pensamento de Maria Vlachou, dando-lhe outra significância: a de torná-lo num documento.

6 Esta publicação compromete o leitor a meditar sobre cultura e impele-o a pesquisar sobre as referências que se encontram em cada artigo. É uma escrita que, concordemos ou não com as afirmações, não nos deixa indiferentes; tira-nos do nosso lugar de conforto e coloca-nos no palco do pensamento e da ação reflexiva. É um livro que nos permite afirmar que incita ao diálogo entre pares e com os públicos.

7 A edição apresenta para cada artigo uma seleção de palavras-chave que se distribuem ao longo dos artigos (nas páginas ímpares) e que servem (ou podem servir) de linha orientadora para o leitor, permitindo igualmente perceber a implicação da cultura (e do pensamento sobre a mesma) em causas globais: direitos humanos, imigração, interpretação, memória, democracia, entre tantas outras citadas ao longo do livro.

8 A organização temática do livro confere-lhe coerência e permite outros diálogos e ligações entre os textos, o que não acontecia no blogue; aqui houve tempo de os agrupar e de os repensar no seu conjunto, providenciando um corpus de pensamento.

o primeiro capítulo, dedicado ao lugar da cultura, reúne cinco artigos com um mote comum: a imperiosa necessidade de mudança de atitude por parte das instituições culturais e dos seus profissionais, problematizando as questões da cultura e a importância da diversidade de práticas culturais; para a autora, o foco das instituições são os públicos, deixando de falar somente para os pares, sob pena de se tornarem irrelevantes. Neste capítulo a autora demonstra um conhecimento elevado do setor cultural, permitindo-se ser acutilante e exigente para com os profissionais da área; a sua reflexão está feita de modo a incomodar, a tentar acordar este setor (que ela apelida de egocêntrico) para que em vez da lamentação possamos em conjunto, profissionais e instituições, dialogar para chegar às pessoas.

10 O segundo capítulo, dedicado à gestão cultural, reúne nove artigos, três dos quais sobre a crise. Nestes, a autora começa por colocar algumas questões, tais como a de ser necessário uma atitude diferente e, em vez de reagir aos cortes, procurar alternativas 
ao modelo até agora vigente. Reforça este incitamento, indicando três lições a retirar do pensamento de Michael Kaiser no seu livro The Art of the Turnaround: Creating and Maintaining Healthy Arts Organizations (2008); a) o maior problema das organizações é a receita e não os custos; b) cortar na iniciativa artística e na comunicação é eliminar a razão pela qual as pessoas trazem receita às organizações culturais; e c) é preciso planear o futuro. Estas lições, segundo Vlachou, são muito importantes e podem ser o ponto de partida para fazer diferente e ter um novo pensamento na gestão cultural em Portugal, sendo para isso necessário mudar práticas. O segundo destes artigos é dedicado aos desafios da programação. Um dos textos mais extensos do livro apresenta uma linha de pensamento muito bem definida e que, mais uma vez, convida os profissionais da cultura ao questionamento das suas práticas, a saírem do seu círculo, a escutar os públicos e, em última instância, a realizar uma programação partilhada e/ou comprometida. $\mathrm{O}$ terceiro artigo desta trilogia é dedicado aos desafios da gestão, onde é colocado o foco na questão da liderança, bem como na capacidade de mudança, de olhar a realidade e, a partir dela, construir novas propostas e não manifestos com linguagens estéreis «que nada propõem, só se queixam», viradas para a classe e não para a sociedade.

11 O terceiro capítulo é dedicado às pessoas, à comunicação e à questão da acessibilidade, reunindo oito textos centrados na questão dos públicos. Podemos afirmar que em todos os textos aqui reunidos o público está sempre presente; é a motivação central da autora, aquela que a leva a refletir sobre a gestão e as práticas e a inquietar-se com a imobilidade e apatia dos profissionais, que segundo Vlachou estão autocentrados.

De forma plural (como em todo o livro) a autora incide sobre questões como os novos públicos e como é importante as instituições culturais repensarem as suas estratégias, olhando para a sua atuação como criadores de pontes, como facilitadores; a questão da criação de hábitos culturais ligada às programações, bem como a necessidade de diversificar mais do que apenas aumentar; a falácia dos números; a questão da importância das equipas terem rostos e da facilidade de comunicação entre equipas e públicos; a criação de relação; os afetos como forma de facilitar a comunicação; as entradas gratuitas nos museus, entre tantas outras questões.

o quarto capítulo é dedicado ao marketing e reúne cinco textos essenciais (nesta conjuntura) para quem trabalha na área cultural, porque desmistifica e problematiza muitas questões relacionadas com a relação entre as instituições e/ou criadores culturais e os seus parceiros, sobretudo os patrocinadores; desde a questão dos logótipos, da imagem, do que o setor cultural tem para oferecer às entidades que o apoiam. As redes sociais como ferramentas e como utilizá-las para ganhar a cumplicidade dos nossos amigos e para os fazer cada vez mais entusiasmados pela nossa instituição/ação.

O quinto capítulo, dedicado aos museus, uma das áreas de especialização da autora, reúne cinco textos de grande acutilância. Numa área em que a bibliografia é, na sua quase totalidade, académica, e na qual não há ensaio, é ainda mais relevante a forma como a autora questiona o papel dos museus na atualidade, levando-os a sair do seu lugar neutro e colocando-os no centro da sociedade, como parte integrante.

Pela leitura realizada, pode afirmar-se que se trata de um livro de leitura obrigatória, pelo olhar diferenciado da autora. Os artigos são curtos e sucintos, mas simultaneamente acutilantes, assertivos e consistentes, levando o leitor a querer que Maria Vlachou continue a escrever, não para dar respostas mas para continuar a 
questionar e a desafiar. Num dos textos a autora diz: «tantas coisas ficaram por dizer, por analisar, por explicar melhor» (p. 91). Numa temática tão vasta é preciso fazer escolhas mas, por outro lado, muitas coisas ficaram ditas, tantos desafios lançados, inúmeras inquietações partilhadas, dezenas de perguntas formuladas, uma imensa frescura de ideias e de olhares partilhados. Da (re)leitura destes textos impõe-se dizer que eles são absolutamente essenciais, neste contexto ou em qualquer outro, para perceber que está nas nossas mãos refletir, definir prioridades e estratégias e mudar «sem esperar de um eterno lá-fora ou lá-longe a solução» (Lourenço 1988, 88).

\section{BIBLIOGRAFIA}

Kaiser, Michael M. 2008. The Art of the Turnaround: Creating and Maintaining Healthy Arts Organizations. Hanover: University Press of New England.

Lourenço, Eduardo. 1988. O Labirinto da Saudade: Psicanálise Mítica do Destino Português. Lisboa: Círculo de Leitores.

\section{NOTAS}

1. Integrou a Comissão Nacional Portuguesa do ICOM entre 2005 e 2014, tendo sido editora do Boletim Informação ICOM-PT. Foi membro fundador do Grupo para a Acessibilidade nos Museus (GAM) e é atualmente a diretora executiva da associação Acesso Cultura (cf. http:// acessocultura.org). É mestre em Museologia (University College London, 1994), com uma tese sobre marketing de museus.

\section{AUTORES}

\section{DÁLIA PAULO}

Câmara Municipal de Loulé, Portugal, daliapaulo@hotmail.com 